\title{
Positive Regulation of Apoptosis
}

National Cancer Institute

\section{Source}

National Cancer Institute. Positive Regulation of Apoptosis. NCI Thesaurus. Code C20150.

Any cellular process that increases the frequency, rate or extent of cell death by apoptosis. 